\title{
O GRUPO MULTIFAMILIAR COMO UM MÉTODO DE INTERVENÇÃO EM SITUAÇÕES DE ABUSO SEXUAL INFANTIL ${ }^{1}$
}

\author{
Liana Fortunato Costa ${ }^{2}$
}

Universidade de Brasília

\author{
Maria Aparecida Penso ${ }^{3}$ e Tânia Mara Campos de Almeida ${ }^{4}$ \\ Universidade Católica de Brasília
}

Neste texto, apresentamos nossa proposta para uma intervenção psicossocial com famílias nas quais ocorreu abuso sexual envolvendo crianças e/ou adolescentes, a partir de uma adaptação de um modelo de Grupo Multifamiliar para esse tipo de contexto. O objetivo geral desse projeto visa a aprofundar e ampliar o conhecimento na área de metodologia de Grupo Multifamiliar, direcionado ao contexto clínico,

1 Trabalho apresentado no X Simpósio de Pesquisa e Intercâmbio Científico da ANPEPP (Associação Nacional de Pesquisa e Pós-graduação em Psicologia), ao Grupo de trabalho "Família e Comunidade", em maio de 2004, em Aracruz, ES. Contamos com a colaboração de Viviane Legnani, psicanalista, Doutora em Psicologia Escolar pela UnB, docente da Universidade Católica de Brasília.

2 Terapeuta Familiar e psicodramatista, Doutora em Psicologia Clínica pela USP, docente do Departamento de Psicologia Clínica do Instituto de Psicologia da UnB. Endereço: SQN 104, Bloco D, ap. 307, Brasília, DF, 70733- 040, Tel: (61) 33287439. Endereço eletrônico: lianaf@terra.com.br

3 Terapeuta Familiar e psicodramatista, Doutora em Psicologia Clínica pela UnB, docente da Universidade Católica de Brasília. Endereço: Rua 08, chácara 214, lote 17, Vicente Pires, Taguatinga Norte, Distrito Federal, DF, 72110-800, Tel: (61) 3597-1071. Endereço eletrônico: penso@ucb.br

4 Doutora em Antropologia pela UnB, docente do Programa de Pós-graduação em Psicologia da Universidade Católica de Brasília. Endereço: SQN 107, Bloco H, apto. 406, Brasília, DF, 70743-080, Tel: (61) 3349-3207. Endereço eletrônico: tmara@pos.ucb.br 
numa modalidade de atendimento especial que ocorre a partir de intimação judicial. Pretendemos, ainda, apontar os limites teóricometodológicos e as possibilidades de trabalhar em Grupo Multifamiliar com a problemática da violência intrafamiliar, mais especificamente, com o abuso sexual envolvendo crianças e seus pais. As crianças, por intermédio de várias estratégias expositivas e expressivas, conseguem indicar como querem e precisam ser cuidadas no dia-a-dia. Por parte dos adultos, ocorre uma melhor compreensão de seus deveres em relação aos cuidados para com suas próprias crianças e as demais da comunidade.

Descritores: Psicoterapia de grupo. Abuso sexual. Intervenção psicoterapêutica. Violência na família.

$\mathrm{N}$ ossa proposta para uma intervenção psicossocial com famílias nas quais ocorreu abuso sexual, envolvendo crianças e/ou adolescentes, teve início a partir da adaptação de um modelo de Grupo Multifamiliar (Costa, 1998a) para esse tipo de contexto. Essa experiência está formalizada no convênio, iniciado em 2002, entre o Laboratório de Psicologia Social e Comunitária do Curso de Graduação de Psicologia da Universidade Católica de Brasília (UCB) e o Setor Psicossocial Forense (SEPAF) do Tribunal de Justiça do Distrito Federal e Territórios (TJDFT).

Tal experiência constitui-se ainda em uma pesquisa interinstitucional, formalizada no Programa de Pós-Graduação em Psicologia na UCB e no Departamento de Psicologia Clínica do Instituto de Psicologia da Universidade de Brasília (PCL/IP/UnB), sob o título Construção de Metodologia de Grupos Multifamiliares no Contexto de Abuso Sexual. Essa pesquisa conta, portanto, com a participação efetiva de professores pesquisadores, alunos de pós-graduação, alunos de pesquisa e alunos estagiários da graduação do curso de Psicologia de ambas as instituições.

Esse trabalho de intervenção e essa pesquisa visam a oferecer subsídios reflexivos e práticos a todos os profissionais que se interessam em compreender as implicações teóricas e metodológicas que envolvem os estudos e a atuação psicossocial em casos de abuso sexual de crianças e adolescentes realizados pela SEPAF. Ou seja, a pedido de um juiz, é feito pelo 
O Grupo Multifamiliar como um Método de Intervenção em Situações...

SEPAF um estudo psicossocial de famílias nas quais ocorreu abuso sexual. Após esse estudo e por determinação judicial, algumas dessas famílias são encaminhadas para atendimento terapêutico pelo convênio com as referidas universidades. Muitas são as questões críticas que solicitam respostas nesse processo de encaminhamento e atendimento - respostas que as universidades se empenham a encontrar, no sentido de auxiliar o SEPAF. Por exemplo, as famílias são obrigadas pelo juiz a procurarem um terapeuta, não possuem condições econômicas para se locomoverem até consultórios e/ou instituições, estão traumatizadas e, geralmente, preferem esconder os acontecimentos, não mais tão recentes, do que expô-los, já que o tempo entre a denúncia e a decisão judicial costuma ser longo.

Como, então, encontrar e viabilizar um modo de encaminhamento mais efetivo? Qual modo de atendimento é mais indicado nesses casos, considerando-se que essas famílias são de baixo poder aquisitivo e pouco vêem o trabalho de um psicólogo como uma fonte de apoio a seus problemas? Como manter o enfoque sistêmico, a família como o cliente, na presença de tema tão sensível? Foram essas, a princípio, algumas das questões críticas que nos fizeram adentrar em um contexto de intervenção tão complexo, mas que também vieram a nos incitar a produzir reflexões inovadoras acerca dessa interface de atribuições entre a Psicologia e o Direito.

Todas as famílias que são encaminhadas para o Grupo Multifamiliar estão envolvidas em casos de litígio, com agravante de abuso sexual (intrafamiliar), ou tiveram algum de seus membros na condição de vítima de violência sexual perpetrada por um agressor externo. Todas elas também foram atendidas pelo SEPAF, por meio de um processo de avaliação (o referido estudo psicossocial), solicitado por um juiz.

O primeiro aspecto fundamental identificado nesse processo de atendimento, contínuo e articulado, é a construção do vínculo com as famílias, que começa a se constituir a partir do encaminhamento judicial. Esse encaminhamento é feito pela equipe da SEPAF, quando percebe ser necessária a continuidade de um atendimento a essas famílias, sendo dada essa conclusão 
em seu parecer, o qual, na maioria das vezes, é acatado pelos juizes responsáveis pelos casos.

A nosso ver, esses magistrados possuem um papel fundamental no encaminhamento dessas famílias, pois as intimam e recomendam o prosseguimento dos atendimentos. Nesse momento, embora saibamos que não existe uma obrigatoriedade prevista em lei para tal atendimento terapêutico, notamos o quanto a figura da justiça, encarnada em seus representantes, simboliza a autoridade, a força, a lei, frente às famílias, asseverando a importância do trabalho (Selosse, 1989). Nem sempre é consenso entre os juízes esse entendimento sobre a obrigatoriedade de atendimento psicológico, sendo assim, a indicação do atendimento psicológico dada pelo juiz, na sentença, não é fundamentada nos termos da obrigatoriedade, mas em termos de sugestão.

Uma outra estratégia para fortalecer a continuidade do atendimento, fora da dimensão de obrigatoriedade, é o fato de que as famílias são acompanhadas, ainda no processo de avaliação, por alunos estagiários, porque o SEPAF também se constitui em área de estágio curricular para cursos de graduação em Psicologia do Distrito Federal. Antes do primeiro contato com as famílias, a equipe, formada por professores e alunos das instituições de ensino superior, encontra-se com a equipe do SEPAF para o conhecimento e repasse das informações acerca das famílias que constituirão o próximo Grupo Multifamiliar.

Esse momento de encaminhamento tem seu ápice num ritual de acolhimento que envolve os profissionais do SEPAF, responsáveis pelo estudo psicossocial (Justiça), e os professores e alunos (Psicologia), promovendo maior segurança às famílias e a garantia de um processo seqüencial ao Grupo Multifamiliar, não dissociado de sua justificativa. Em nossa opinião, esse ritual (Bergman, 1986) é fundamental e dá início ao contrato extra, e intramembros do Grupo Multifamiliar, construído em conjunto, Justiça e Psicologia, equipes e famílias, com formalidades como convites, constando endereço, contato telefônico, datas e horários dos encontros. Nesse primeiro momento, ocorrem apresentações das famílias entre si e delas com a equipe, bem como é exposta a proposta de trabalho. Além disto, podem ser convi- 
O Grupo Multifamiliar como um Método de Intervenção em Situações...

dadas a participar desse ritual famílias que já integraram um Grupo Multifamiliar anterior (experiência em curso).

Em linhas gerais, os atendimentos do Grupo Multifamiliar fundamentam-se nos seguintes aportes teóricos:

a) da Psicologia Comunitária, visando ao trabalho em equipe com diferentes saberes, científicos e populares (Santos, 1999), e o enfoque na Psicologia Social Crítica e Histórica (Lane \& Sawaia, 1995), percebendo o ser humano em construção, que é constituído e constitui o meio em que se insere;

b) da Terapia Familiar, tendo a visão de família enquanto sistema, sendo a relação o ponto focal do trabalho, priorizando o interpsíquico mais que o intrapsíquico, e utilizando os recursos sistêmicos como a circularização e a provocação (Minuchin, Colapinto, \& Minuchin, 1999);

c) do Sociodrama, em que o grupo é o protagonista e as famílias possuem objetivos comuns, além de se identificarem mutuamente (Moreno, 1993); e

d) da Teoria das Redes Sociais, que enfoca a interação humana com a troca de experiência, desenvolvendo a capacidade auto-reflexiva e autocrítica (Sluzki, 1996).

Partimos, ainda, da proposta de Saidón (1995), para quem pensar em rede é acreditar que já existe uma rede natural de relações na qual as famílias já estão inseridas. Logo, reconhecemos que as possibilidades de soluções estão na própria rede natural e espontânea, que pode oferecer e mobilizar o desenvolvimento e as mudanças tanto individuais como grupais.

\section{Caracterização do Problema e Justificativas}

A questão do abuso sexual de menores em contexto intrafamiliar é uma problemática que, cada vez mais, vem a público. Com o advento da denúncia anônima, esse tipo de conflito, que está mais afeito à vida privada, vem sendo muito mais encaminhado ao contexto judicial, exigindo as providências oriundas da esfera pública. 
Em países de primeiro mundo, o atendimento terapêutico nesse contexto é realizado sob obrigação (Cirillo \& Di Blasio, 1991; Madanes, Keim, \& Smelser, 1997; Selosse, 1989). No Brasil, a legislação não oferece elementos para a exigência dessa obrigatoriedade. Sendo assim, a UCB, a UnB e o SEPAF fizeram um convênio para a realização de um trabalho pioneiro, constituído pelo oferecimento de Grupos Multifamiliares para as famílias que passaram por uma avaliação psicossocial na Vara de Família desse Tribunal, e nas quais foi apontada a existência de conflito familiar, envolvendo crianças e/ou adolescentes abusadas sexualmente.

Um dos aspectos do referido pioneirismo se deve ao fato de que realizamos uma adaptação original de outras experiências de construção de metodologia de Grupo Multifamiliar, em contexto de baixa renda e atendimento sob obrigação, como indica a literatura publicada por pesquisadores brasileiros (Costa, 1998a, 1998b, 1998/1999, 1999; Holzmann \& Grassano, 2002; Póvoa \& Sudbrack, 2003).

Em recente publicação, Faleiros (2003), pesquisando sobre a trajetória das denúncias de abuso sexual, encontra um grande espaço de tempo entre a denúncia e o término do processo (de 3 a 5 anos) e uma falta de condições de encaminhamento para atendimento dessa população. Nesse sentido, a pesquisa que desenvolvemos vem oferecer respostas também pioneiras ao impasse do atendimento, tanto do ponto de vista de uma metodologia apropriada a processos que ainda se encontram em andamento na justiça, quanto do ponto de vista do oferecimento de ações que colaboram com o melhor desfecho dos casos na justiça.

Por isso, acreditamos que, em relação ao nível de contribuição tecnológica oferecido pelo projeto em questão, a elaboração dessa metodologia traz inúmeros benefícios para o conjunto de instituições governamentais e não-governamentais que integram a rede de atendimento e de diagnóstico sobre esse tema. Afinal, a temática do abuso sexual segue sendo um problema que toca a intimidade dos participantes, o que gera uma enorme dificuldade em se conhecer e divulgar avanços sobre a resolução dos conflitos que subjazem ao abuso. Desse modo, há uma grande potencialidade de apli- 
O Grupo Multifamiliar como um Método de Intervenção em Situações...

cação da nossa metodologia, uma vez que os grupos profissionais e institucionais que trabalham nesse âmbito encontram-se carentes de informações, reflexões e publicações sobre essa área de conhecimento.

Pode-se relacionar, ainda, na condição de mecanismos de transferência dessa tecnologia, os treinamentos, os fóruns de debates, os cursos, os materiais impressos, as comunicações orais e as reuniões de trabalhos conjuntas com os técnicos do TJDFT. A equipe que propôs inicialmente a pesquisa segue sendo a responsável pela implementação, desenvolvimento e avaliação da referida metodologia, no próprio TJDFT e em outros âmbitos que venham a ter interesse nesse produto.

Com relação aos impactos provocados por ela, identificamos a sua presença em três planos. Primeiramente, vislumbramos que, no que diz respeito à parceria com o TJDFT, o estudo dessa metodologia influencie novos procedimentos de avaliação psicossocial que estão sendo adotados atualmente, possibilitando que alguns recursos judiciais sejam implementados, tais como atendimentos de tutela e guarda, que podem, em alguns casos, ser realizados em grupos. Em segundo lugar, no que diz respeito ao conjunto de instituições e profissionais que trabalham em atendimentos clínicos a essa população, também esperamos a emergência de avanços nas práticas e possibilidades de inovações nos atendimentos, bem como a emergência de avanços nas reflexões teóricas e na formação de psicólogos mais talhados para atuarem nesse contexto. Por fim, no que diz respeito às famílias atendidas, podemos esperar transformações em suas interações, bem como divulgação do potencial de recuperação de cidadania e bem-estar a partir das intervenções do grupo.

Grosso modo, por conseguinte, podemos sintetizar o problema para o qual dirigimos a pesquisa da seguinte forma: criação de uma metodologia de atendimento familiar em grupo, em casos de abuso sexual envolvendo crianças e/ou adolescentes, própria para esse tipo de problemática e passível de ser difundida e aplicada a outras situações correlatas.

Quanto ao objetivo geral desse projeto, visa a aprofundar e ampliar o conhecimento na área de metodologia de Grupo Multifamiliar, direcionado 
ao contexto clínico, numa modalidade de atendimento especial que ocorre a partir de intimação judicial. Quanto aos objetivos específicos, pretendemos descrever a adaptação feita com a experiência do Grupo Multifamiliar (Costa, 1998a, 1998b, 1998/1999, 1999, 2003) para famílias de baixa renda no contexto clínico; compreender melhor a dimensão de sofrimento presente nessas famílias; aprofundar a compreensão acerca da proteção/desproteção devida às crianças e aos adolescentes; dar continuidade ao trabalho iniciado no SEPAF; e, também, conhecer o modo como implementar a auto-reflexão do abusador e a co-participação de outros membros da família, em especial da mãe. Pretendemos, ainda, apontar os limites teórico-metodológicos e as possibilidades de trabalhar em Grupo Multifamiliar com a problemática da violência intrafamiliar, mais especificamente, com o abuso sexual envolvendo crianças e seus pais.

\section{Quadro metodológico: a pesquisa - ação}

Situamos nosso trabalho dentro do quadro metodológico da pesquisaação. Hollanda (1993), pesquisadora da área de saúde pública, encara a pesquisa-ação como uma ação social voltada à resolução de problema coletivo. A perspectiva da pesquisa-ação inclui a participação efetiva da população-alvo, no seu processo de educação coletiva, e a utilização desse método em favor de camadas mais despossuídas, cujo objetivo central é a mudança social.

Thiollent (1986) define a pesquisa-ação como um tipo de pesquisa social que é planejada e realizada em estreita associação entre pesquisadores e participantes, sendo que ambos estão nela envolvidos de forma cooperativa ou participativa. Hollanda (1993) e Thiollent (1986) preocupam-se com a distinção entre pesquisa-ação e pesquisa participante, mostrando que essa última se caracteriza mais por promover uma motivação na população pesquisada, no sentido de estimulá-la a participar como agente ativo em seu universo social. Barbier (2002) aponta a pesquisa-ação como uma verdadeira transformação da maneira de conceber e de fazer pesquisa em Ciências Humanas. 
O Grupo Multifamiliar como um Método de Intervenção em Situações...

Em busca de se alcançar os objetivos da pesquisa-ação, nossa proposta de Grupo Multifamiliar recebeu o formato de quatro ou cinco sessões, com duração de três horas cada uma. O grupo é constituído por quatro a cinco famílias e possui os seguintes recursos de registro: sala com espelho unidirecional, gravação e filmagem. A equipe de atendimento é formada por professores supervisores, alunos de pós-graduação e graduação do curso de Psicologia. Contamos, ainda, com duas ou três salas auxiliares durante o atendimento, para divisão do grupo em pequenos subgrupos.

Sendo um dos objetivos do grupo dar continuidade ao trabalho iniciado no SEPAF, os temas dos encontros buscam avançar as questões relacionadas à proteção e ao cuidado às crianças, restabelecer a auto-estima dos membros das famílias, trabalhar a dimensão transgeracional do abuso e a responsabilização dos pais, bem como oferecer um espaço de expressão do sofrimento para que haja mudanças na vida intrafamiliar, possibilitando um projeto de compromisso futuro.

O Grupo Multifamiliar desenvolve-se com ênfase no aspecto lúdico por intermédio de jogos dramáticos (Monteiro, 1979; Motta, 1995; Yozo, 1996). Nestes, os dramas concretos são intermediados pelos jogos, produzindo a vivência sensibilizada; com uma preocupação num enfoque de responsabilização pela presença da violência na família; maior atenção à voz e vez das crianças, entendendo que todos participam do grupo - portanto, também produzem situações novas e reproduzem outras antigas, bem como as compartilham. Além disso, procuramos dar ênfase no papel de cuidadora das mães, pois, na maioria dos casos, são elas que estão mais presentes no cotidiano doméstico e assumem cuidados diretos com as crianças.

A metodologia utilizada é uma adaptação da sessão psicodramática (Costa, 1998a), que se desenvolve em três etapas bem definidas. A primeira etapa consiste num momento de aquecimento, no qual todas as famílias estão juntas, e se procura atingir melhor integração grupal, bem como aquecer todos para o aprofundamento do tema específico daquele dia (por exemplo, dar proteção e pedir proteção). Esse aquecimento é realizado por meio de jogos dramáticos. 
A segunda etapa é aquela na qual se busca maior aprofundamento de um dos objetivos do grupo, por meio da subdivisão em subgrupos de adultos, adolescentes e crianças (em função da distinção das faixas etárias). Seus objetivos são aqueles já apontados no parágrafo anterior. A atividade se passa por meio de jogos, dramatizações, discussões, conforme a adequação ao subgrupo, sendo que, ao final dessa etapa, cada subgrupo prepara um informe de sua produção para ser apresentado aos demais.

A terceira etapa consiste na reunião de todos os participantes novamente, a fim de compartilharem essa produção variada, para que todos tenham conhecimento do que cada um pensa sobre os temas daquele dia. É momento também para que os pais possam falar aos filhos e os filhos aos pais, ou que adultos e crianças emitam suas opiniões ao coletivo e sejam aí escutados. O Grupo Multifamiliar se encerra com um ritual, no qual é privilegiado um compromisso com o tema desenvolvido no dia, por exemplo, todos se comprometem a prestar mais atenção à proteção das crianças e essas, por sua vez, se comprometem a pedir ajuda aos pais, quando se sentirem ameaçadas.

O desenrolar da metodologia do Grupo Multifamiliar é ativado a partir da ênfase na dimensão lúdica, como já foi dito, com uma preocupação na responsabilização de todos com relação aos membros violentados na família, e com maior atenção à voz e vez das crianças em cada sessão. Procuramos, todo o tempo, enfatizar o papel de cuidadora das mães ou de algum(a) substituto(a) dessa, mobilizando-os diante dos temas acima relacionados.

A metodologia permite que alcancemos esses objetivos, ao se discutir os temas dentro de subsistemas de forma bem específica. Assim, podemos agrupar as mulheres adultas ou as crianças ou os adolescentes, ou, ainda, o subsistema feminino ou o subsistema masculino, conforme as necessidades de se trabalhar o tema do dia de modo mais pertinente à dinâmica de cada Grupo Multifamiliar.

Nessa pesquisa, as ações previstas são: 1) contatos com o SEPAF do TJDFT, firmando a parceria já existente; 2) indicação das famílias para comporem o Grupo Multifamiliar por parte do TJDFT; 3) reunião de discussão dos dados informativos sobre cada família a compor o Grupo Multifami- 
O Grupo Multifamiliar como um Método de Intervenção em Situações...

liar nas dependências do TJDFT, com a presença das equipes do TJDFT e da pesquisa; 4) rito de recebimento e passagem das famílias indicadas para o Grupo Multifamiliar nas dependências do TJDFT, com a presença das equipes do TJDFT e da pesquisa; 5) operacionalização dos atendimentos de Grupos Multifamiliares, previstos de 4 a 5 por semestre, quinzenais, nas dependências das clínicas-escola das universidades, com a equipe da pesquisa; 6) realização de relatórios por Grupo Multifamiliar a ser enviado para o TJDFT, contendo a freqüência; 7) ao longo de todas as etapas, serão realizadas revisões bibliográficas, reuniões de estudo, reuniões de supervisão e de avaliação final dos dados coletados; 8) todos os Grupos Multifamiliares serão registrados em vídeo, para posterior transcrição e análise; 9) realização de Fórum de Debates, juntamente com o pessoal do TJDFT, sobre os resultados da pesquisa; 10) divulgação dos resultados em publicações e eventos técnico-científicos; e 11) consolidação da metodologia a ser desenvolvida.

Concomitantemente à execução dessas etapas, temos os seguintes produtos esperados:

a) No campo da ação: oferecer uma ação, já descrita, que consolidará o convênio com o TJDFT; oferecer treinamento técnico a estagiários do curso de graduação em Psicologia; acrescentar e consolidar experiência e conhecimento a outras pesquisas, já em andamento, por ambos os programas de pós-graduação da UCB e da UnB; oferecer atendimento a famílias carentes da comunidade, que, dificilmente, poderiam usufruir desse tipo de atendimento, caso fosse pago; e estabelecer com o TJDFT um fórum de trocas teóricas e metodológicas já previstas no convênio, que se ampliariam para outras instituições, como a Vara de Infância e Adolescência - VIJ - e o Hospital Regional da Asa Sul - HRAS -, por conta das parcerias do TJDFT com essas instituições.

b) No campo da pesquisa: descrever e incluir na literatura já existente conteúdo teórico-metodológico sobre o tema da violência intrafamiliar; publicar e apresentar em congressos os resultados, visando a ampliar a discussão acerca da efetividade de Grupos Multifamiliares em outros contextos, que não os já pesquisados; possibilitar trocas com outros pesquisadores que 
se interessam tanto pelo tema da violência intrafamiliar quanto pelos processos metodológicos de condução, manejo e reestruturação de grupos que envolvam várias famílias, simultaneamente.

\section{Considerações sobre os resultados alcançados}

Quanto às metas propostas no projeto

Até o momento, atendemos 25 famílias ao longo desses três anos, por intermédio do oferecimento de 1 a 2 Grupos Multifamiliares por semestre. Essas 25 famílias representam de 50 a 60 adultos, cerca de 100 crianças e 50 a 60 adolescentes. Com relação aos alunos de estágio regular de graduação, contamos com a participação de 10 alunos em cada semestre, o que totaliza 20 alunos de graduação ano. Oferecemos ainda 3 bolsas de Iniciação Científica (IC) por semestre, vagas para alunos voluntários de pesquisa da graduação e para profissionais voluntários da comunidade, que desejam ser treinados na metodologia. Com relação aos alunos da pós-graduação, oferecemos condições para coleta de informações, elaboração de projetos de mestrado e doutorado, para, no mínimo, dois alunos por semestre. O grupo também oferece condições de observação para 4 a 5 alunos de graduação, que se encontram na fase de elaboração de Trabalho de Final de Curso.

Nesses três anos, aconteceram quatro reuniões conjuntas - UCB, UnB , TJDFT com o objetivo de discussão teórico-metodológica com os profissionais do TJDFT, o que implicou a presença de aproximadamente 20 profissionais do tribunal e da equipe interdisciplinar da pesquisa. Desse modo, as reuniões também viabilizaram a construção e o acompanhamento da parceria com o TJDFT. Dentro desses encontros, ocorreu um Fórum de Debates que incluiu a participação da equipe de pesquisadores, os profissionais do TJDFT e os juízes, promotores e advogados integrantes das várias instâncias judiciais (Costa, Penso \& Almeida, 2002).

Realizamos duas grandes revisões de literatura sobre o tema de pesquisa, as quais subsidiaram a elaboração de artigos: Costa, Penso, Gramkow, 
O Grupo Multifamiliar como um Método de Intervenção em Situações...

Santana, \& Ferro (2003); Costa, Penso, \& Almeida (2004); Costa, Santana, Gramkow, \& Ferro (2005); Penso, Legnani, Costa, \& Antunes (2005); Penso, Costa, \& Almeida (2005).

Houve, também, a elaboração de comunicações em eventos: no Seminário Interno de Psicologia na UCB e na VI Conferência Internacional sobre Filosofia, Psiquiatria e Psicologia, ambos ocorridos em 2003. Nesses seminários, a equipe se responsabilizou pela apresentação e coordenação da Mesa Redonda "Linguagens Particulares e Sofrimento em Casos de Violência Intrafamiliar", com os seguintes trabalhos: "Violência intrafamiliar: uma análise da dinâmica das famílias violentas”; “Os contextos jurídico e terapêutico em casos de violência intrafamiliar: possibilidades e limites”; e "A narrativa religiosa sobre um caso de estupro incestuoso”.

\section{Quanto aos aspectos qualitativos da pesquisa}

Em nossa experiência, podemos perceber a intervenção em grupos, com as famílias e seus filhos adolescentes e crianças, enquanto um espaço de grandes e boas possibilidades de êxito na reversão do quadro de violência sexual. Afinal, as crianças, por intermédio de várias estratégias expositivas, conseguem indicar como querem e precisam ser cuidadas no dia-a-dia. Simultaneamente, por parte dos adultos, ocorre uma melhor compreensão de seus deveres em relação aos cuidados com suas crianças e com as da comunidade.

Adentramos, assim, numa dimensão socioeducativa, quando realizamos dramatizações sobre os Direitos Universais das Crianças (UNICEF, 2001) e procuramos fazer um treinamento de dizer "Não". Este envolve, principalmente, as crianças, com relação ao desrespeito aos seus direitos e ao seu bem-estar, assim como o esclarecimento de quais partes do seu corpo podem, ou não, ser tocadas por adultos em estratégias de atração, envolvimento e sedução. Enfim, buscamos oferecer condições de acolhimento ao sofrimento específico das crianças, sua reelaboração no seio familiar e condições de criação de barreiras eficazes para o seu prosseguimento. 
O Grupo Multifamiliar também oferece possibilidades de compreensão e intervenção nas dificuldades conjugais. Ou seja, o abuso sexual infantil traz à tona uma expressão clara de desajustes conjugais preexistentes ou fornece condições de desgaste emocional para o surgimento de conflitos como disputa de razão, estabelecimento de poder e acusações mútuas, indicando a necessidade de o casal realizar um resgate de uma conversação transformadora sobre si mesmo, tendo o evento da violência como porta de acesso a ela (Anderson \& Goolishian, 1993).

Essa conversa deve incluir um aprofundamento da relação do casal sobre sentimentos e emoções, tais como: culpa, medo, silêncio, fantasia de vingança e repressão dos afetos, além da recuperação da intimidade conjugal, proporcionando aproximação e união - ou, pelo menos, melhor capacidade de diálogo e equilíbrio, quando os pais das vítimas não mais se encontram em vida matrimonial. Consideramos fundamental a atualização e a harmonia da relação conjugal nesses casos de abuso sexual infantil, seja por membro externo ou interno à família.

Outro resultado visível importante é o fato de que a metodologia em questão oferece condições para a revisão e a reconstrução das relações entre pais e filhos. As conversações entre gerações, base desse tipo de trabalho, nos dão a oportunidade de realizar uma reflexão sobre as relações entre pais e filhos, tendo ênfase no resgate da dimensão do respeito mútuo. Vemos que tal resgate é possível ao se favorecer a reelaboração dos papéis de protetor e de cuidador junto aos pais, a partir de seu repensar sobre suas próprias histórias, especificamente nas experiências vividas no papel de filho e filha.

Essa possibilidade surgiu, ao entendermos como parte de nossa responsabilidade na atuação como coordenadoras do Grupo Multifamiliar, a criação e mediação de um espaço de conversação, que traga novas dimensões do sofrimento familiar, em especial, uma perspectiva transgeracional da violência. Ou seja, tentamos trazer à tona, nos atendimentos, o fato de que os pais abusadores ou negligentes, provavelmente, apreenderam essas formas de relacionamento intrafamiliar quando eles mesmos eram crianças. No passado, em suas infâncias e adolescências, inscreveram tais comportamentos, senti- 
O Grupo Multifamiliar como um Método de Intervenção em Situações...

mentos e atitudes em suas memórias, que foram modelares para o desempenho de suas atuações maternas e paternas nos dias de hoje.

Por isso, Ravazzola (1997) afirma que, em tais casos de violência, todos são vítimas - aquelas pessoas que sofrem a violação atual, seus perpetradores e a família na qual eles ocorrem. Todos os envolvidos, portanto, merecem atenção e suporte psicológico dos profissionais e das instituições competentes.

\section{Quanto aos impactos éticos e políticos na comunidade}

Percebemos, ainda, esse espaço de conversação do Grupo Multifamiliar como um espaço de possibilidades sobre a reconstrução do que estamos denominando de cidadania ferida, uma vez que o aspecto sociopolítico da violência sexual deve ser evidenciado, discutido e tratado no âmbito das ações públicas. As dolorosas e complexas situações humanas, presentes nos acontecimentos do abuso sexual infantil, requerem que a sociedade dê atenção tanto à vítima quanto ao abusador, apoiando-os em processos de ressimbolização e recuperação de suas trajetórias individuais e familiares, de modo a favorecer a irrupção de atores sociais íntegros, responsáveis e saudáveis.

Na verdade, por intermédio dessa atenção, esperamos que tais pessoas possam assumir a posição ativa de sujeitos de suas histórias, agindo de modo a não apenas reproduzir os modelos apreendidos e introjetados hoje, no caso das crianças, ou no passado, no caso dos adultos envolvidos. Para tanto, é fundamental assegurar-lhes, em estruturas e recursos apropriados, a participação plena e consciente nas decisões e nos processos que lhes afetam diretamente, rompendo muitas vezes com padrões antigos. Trata-se aqui de possibilitar-lhes um mecanismo de atribuição de poder (empowerment) (PNUD, 1996).

Demo (1991, 1996) é enfático ao comentar sobre a constituição da cidadania em nosso país. Uma substancial parcela da sociedade vem vivendo, durante gerações seguidas, somente com o recebimento e sob o impacto de 
medidas de caráter assistencialista, caracterizando muito mais a consolidação de uma cidadania assistida e tutelada do que a expressão de uma cidadania plena de direitos e deveres.

Soma-se a esse comentário a reflexão de Moreira das Neves (2000) sobre os avanços na legislação portuguesa em relação à responsabilização em casos de abuso sexual. Ou seja, sua afirmação enuncia a necessidade de a sociedade assumir o cuidado tanto da vítima quanto do agressor, oferecendo a oportunidade desse último receber atendimento apropriado. É fundamental a atribuição da natureza pública ao crime da violência sexual. Colocamo-nos ao lado desse juiz português, indicando que se faz urgente tal oferecimento, porque o agressor também demanda um espaço de compreensão de suas ações, no âmbito da sociabilidade e desde que essas ações são desenvolvidas em longos processos socioculturais por eles vivenciados, evidenciando nos indivíduos as marcas de seus contextos mais amplos e de suas histórias transgeracionais.

Além disso, cabe ressaltar que as vítimas de agressão sexual e seus familiares, via de regra, têm seus espaços de locomoção bastante restringidos pelas ameaças dos agressores externos que permanecem na impunidade. Empenhamo-nos em enfocar uma conversação que resgate o direito fundamental de ir e vir das famílias e, também, das pessoas que participaram das denúncias, em geral, alguém bem próximo da família. Não basta a polícia ou a justiça darem acolhimento a denúncias, é preciso que ofereçam espaços de proteção física e emocional, porque há muito constrangimento vivido por parte das vítimas no trato com os abusadores que permanecem inseridos no cotidiano do contexto familiar ou comunitário.

A experiência das famílias, ao relatarem as muitas idas e vindas às delegacias, aos juizados ou às audiências, nos mostra que esse evento e suas conseqüências policiais e jurídicas acabam por colocar as famílias na condição de cidadania restrita, ou seja, tutelada e assistida. Assistidas pelo aparato policial e judicial, é verdade, mas também tuteladas e submetidas às limitações e precariedades desses mesmos aparatos, ao dependerem deles diretamente. 
O Grupo Multifamiliar como um Método de Intervenção em Situações...

\section{Violência e o desafio da interdisciplinaridade}

Um importante desafio que esse tipo de trabalho nos impõe é a elaboração de ações e reflexões interdisciplinares, vinculando, entre si, duas grandes áreas de intervenção com diferentes paradigmas, como são a Psicologia e o Direito. A Psicologia pauta-se por uma busca compreensiva das ações humanas em searas que vão do indivíduo aos seus respectivos contextos socioculturais, enquanto o Direito busca normas e parâmetros já legitimados na sociedade como fundamento e meta de suas decisões. Por conseguinte, em linhas gerais, podemos afirmar que a Psicologia interpreta e atua na dimensão psicossocial do problema da violência sexual, enquanto o Direito legisla nesses casos, muitas vezes, tomando por subsídio a interpretação oferecida pela Psicologia aos seus oficiantes.

Como, então, aproximar e reconhecer os limites e as possibilidades dessa parceria? Pensamos que o Direito, por intermédio da sua dimensão decisória, favorece e mesmo ajuda a Psicologia a fazer o resgate do sentido reparador da desproteção com a criança, que ocorre nessas famílias, quando é possível a expressão das emoções em palavras e a reelaboração da vivência com o outro dentro de um profundo processo de mudança. A decisão judicial de encaminhar as famílias para atendimento possibilita a inclusão social dessas pessoas, levando a Psicologia a assumir um papel diferente daquele que apenas realiza diagnósticos para a justiça. Esse saber passa a atuar diretamente na reconstrução de significados e sentidos presentes nos atos de violência, vinculando-se a um novo compromisso ético-político dentro da sociedade (Costa, Penso, \& Almeida, 2003).

Dentre a enorme gama de significados reconstruídos, chama-nos a atenção o redirecionamento do olhar sobre o abusador dentro da própria justiça. A partir dessas reflexões da Psicologia, juízes e outros legisladores começam a entender atos de violência sexual, em especial, aqueles ocorridos no seio familiar, enquanto resultados não apenas de crimes hediondos, isolados de contextos socioculturais e inumanos. Ou seja, esses atos ganharam sentidos novos ao serem compreendidos dentro de uma perspectiva humana 
e de uma dinâmica familiar e transgeracional, levando seus perpetradores a receberem outras penas e tipos de tratamentos, que podem produzir resultados mais eficazes.

A reconstrução e a ampliação desse significado, proporcionadas pelos estudos da Psicologia, vêm revolucionando a Justiça, abrindo a possibilidade de que haja garantia de novos direitos de cidadania não apenas às vítimas, como também aos seus próprios agressores. Por conseguinte, esse movimento de ressignificação acaba por implicar a sociedade, em suas diversas instituições, de modo que se comprometa a oferecer suporte efetivo, proteção e encaminhamento a vítimas e agressores - ambos vistos, agora, como sujeitos de plenos direitos.

Assim, vimos assinalando a importância de uma continuidade da intervenção psicossocial fora do contexto jurídico, resgatando a certeza da proteção permanente e integral para todos aqueles envolvidos no ato de violência, a partir de um trabalho conjunto entre a Psicologia e o Direito. Logo, o envolvimento de toda a família e do seu entorno comunitário nos Grupos Multifamiliares, por um lado, facilita a implantação de estratégias eficazes, em diversas dimensões, do apoio às crianças e aos adolescentes para que possam seguir suas vidas sem danos psíquicos profundos e impeditivos do exercício pleno da cidadania. Por outro lado, facilita a imposição de limites e a oportunidade de tratamento aos já agressores e potenciais agressores dentro de recursos socioculturais da própria rede familiar e comunitária.

Quando o agressor é interno à família, faz-se necessário que se restabeleça a circulação do afeto entre os seus membros, demarcando as fronteiras intergeracionais, bem como os papéis e as regras familiares. A família, nesses casos, ressente-se de uma exclusão frente aos vizinhos e à comunidade e necessita de um trabalho específico de re-inserção social a partir do evento. Muitas vezes, as famílias permanecem presas ao silêncio, ao nãodito e ao não-interpretado (Bandeira \& Almeida, 1999).

Quando o abusador é externo à família, ocorre um acréscimo da experiência da violência, trazida pelo andamento dos processos policial e judicial. As famílias se queixam de que se sentem violentadas pela constatação do 
O Grupo Multifamiliar como um Método de Intervenção em Situações...

favorecimento à liberdade dos agressores. Nesse caso, questionamos quais medidas ainda podem ser tomadas em conjunto, pela Psicologia e pelo Direito, no sentido de potencializar as reivindicações das famílias por uma vida cidadã, para que vítimas não sejam transformadas em algozes e responsáveis pelos atos violentos ocorridos com seus filhos.

\section{A Intervenção Psicossocial: Desdobramentos e Questões}

Na realização do trabalho com essas famílias, surgem muitas questões sobre a intervenção psicossocial no contexto do abuso sexual. Uma das questões que nos tem proporcionado muitas discussões diz respeito a intervenções específicas com o sujeito abusador, compreendido, aqui, como alguém também portador de sofrimento psíquico. Em um dos casos atendidos, tivemos a presença de um suposto pai abusador nos Grupos Multifamiliares e foi muito importante trabalhar os vínculos desse pai com seus filhos (possivelmente abusados por ele).

Temos situações específicas e diversificadas. Quando o abusador é alguém da família (pai, padrasto, tio etc), além da vergonha, medo e dor de seus membros, muitas vezes, a criança é afastada desse familiar. Além disso, muitos desses abusadores, em função da denúncia, são presos, dificultandolhes, assim, qualquer intervenção e apoio psicológico. Mesmo com essas limitações, compreendemos a importância de se pensar em propostas de ações específicas para esses abusadores, procurando conhecer sua realidade e seu possível sofrimento. Quando o abusador é alguém externo à família, a possibilidade dessa intervenção é mais remota, já que, de modo geral, envolve outros níveis de relações entre a família da criança abusada e o abusador.

Outra questão diz respeito às diferentes significações atribuídas ao ato pela família, no contato com o juiz, nos atendimentos no Setor Psicossocial Forense e no Grupo Multifamiliar, que apontam para possibilidades de construção de novas narrativas sobre o fato ocorrido. Temos observado, no Grupo Multifamiliar, como as famílias, a partir de uma reflexão sobre o ato e sobre o seu funcionamento, ao longo dos anos, conseguem transformar a compreen- 
são de suas histórias, mudando os modos de se relacionarem internamente. A possibilidade de múltiplos olhares sobre o ato permite discutir sobre a complexidade das situações vividas, além de validar a importância de equipes multiprofissionais e de intervenções em diferentes âmbitos e contextos.

Mais do que uma hipótese, uma certeza que temos tido, ao longo das atividades com Grupos Multifamiliares, é do enorme valor do trabalho com as crianças, nas quais os efeitos estão presentes na fala, a partir de suas reivindicações explícitas por proteção. Ao sentirem-se compreendidas e apoiadas no grupo, elas se permitem reivindicar seus direitos a cuidados e proteção e, também, questionam seus pais sobre a forma como vêm sendo educadas. Por último, a intervenção psicossocial levanta questionamentos sobre os aspectos éticos do trabalho, já que, em razão da sua complexidade e do significativo número de instituições sociais envolvidas, pressupõe diferentes compreensões da realidade, bem como intervenções diferenciadas, conforme afirmamos anteriormente.

Com relação ao processo do Grupo Multifamiliar, pressupomos a Ética do Compromisso: troca lógica da importância do sigilo privado pela do compromisso público, no qual se privilegiam as soluções e as relações a partir das experiências e vivências de diferentes pessoas. Nossa posição baseia-se em Maturana \& Verden-Zöller (1997), que buscam definir uma maneira "matrística” (p. 65) de viver, ou seja, um espaço de convivência, aceitação e legitimidade de todas as maneiras de se viver, de acordo com a geração de um projeto comum de coexistência. Essa maneira matrística de ver a vida nos abre a possibilidade de compreender a natureza, a partir da integração e co-participação de todos os seres vivos no fluxo da vida.

No que diz respeito às diferentes instâncias envolvidas no trabalho que estamos desenvolvendo, partimos do pressuposto da complexidade, ao percebermos que a simplificação obscurece as inter-relações existentes entre todos os fenômenos do universo (Vasconcellos, 2002). Por isso, ao se compreender a impossibilidade de um conhecimento único e objetivo sobre o mundo, podemos nos situar de modo profícuo na interface da Psicologia com o Direito, respeitando as suas diferentes interpretações possíveis sobre 
O Grupo Multifamiliar como um Método de Intervenção em Situações...

os fatos. Respeito esse que se dá por não vê-las de modo excludente, mas complementar, confluindo as interpretações em ações concretas de intervenção jurídica e psicossocial, que auxiliem famílias oriundas de situações traumáticas de violência sexual a resgatarem o seu valor próprio e a recuperarem sua cidadania plena. Para tanto, vimos trabalhando em cada atendimento do Grupo Multifamiliar no intuito de se fazerem reconhecer e de serem reconhecidas como sujeitos de plenos direitos.

A partir de tais resultados, visamos a ampliar a discussão acerca da efetividade de Grupos Multifamiliares em outros contextos, que não os pesquisados até o momento. Esperamos, também, efetuar trocas com outros pesquisadores que se interessam tanto pelo tema da violência intrafamiliar e do abuso de crianças/adolescentes quanto pelos processos metodológicos de condução, manejo e reestruturação de grupos, reunindo em torno de si várias famílias, simultaneamente.

Costa, L. F., Penso, M. A., \& Almeida, T. M. C. (2005). The multifamiliar group as a method of intervention in situations of child sexual abuse. Psicologia USP, 16 (4), 121-146.

Abstract: We present in this text our proposal for a psycosocial intervention in families in which sexual abuse occurred involving children and/or teenagers, as from an adaptation of a model of Multifamiliar Group for this type of context. The general objective of this project aims at deepening and increasing the knowledge in the area of methodology of Multifamiliar Group directed to the clinical context, in a modality of special attendance which occurs as from judiciary demand. We still intend to point out the methodological-theoretical limits and the possibilities of working in Multifamiliar Group with the intrafamiliar violence problem, more specifically with sexual abuse involving children and their parents. Children, by means of various expositive and expressive strategies, can indicate how they wish and need to be cared for in their everyday life. On the part of adults, there occurs a better comprehension of their duties in relation to the cares with their own children and the others of the community.

Index Terms: Group psychotherapy. Sexual abuse. Psychotherapeutic intervention. Family violence. 
Costa, L. F., Penso, M. A., \& Almeida, T. M. C. (2005). Le group multifamilial comme une méthode d' intervention en situations d'abus sexuel infantile. Psicologia USP, 16 (4), 121-146.

Résumé : Nous présentons, dans ce texte, notre proposition pour une intervention psychosociale dans des familles dans lesquelles le harcèlement sexuel des enfants et/or des adolescents a eu lieu. Il s'agit d'une adaptation d'un model de Group Multifamilial, pour ce contexte. L'objective général de ce projet est celui d'approfondir et amplifier la connaissance dans le domaine de la méthodologie de Group Familial destiné au contexte clinique, selon une modalité de consultation spéciale de mandat d'amener. Nous prétendons aussi montrer les limites théoriques et méthodologiques ainsi que les possibilités de travailler en tant que Group Multifamilial avec la problématique de la violence intra familial, spécifiquement dans ce qui concerne le harcèlement sexuel des enfants par leurs parents. Les enfants, à travers des stratégies expressives, arrivent à indiquer la façon dont ils veulent être soignés le jour à jour. De la part des adultes, il y a une compréhension améliorée de leurs devoirs

Mots-clés: Psychoterapie de Group. Abuse sexuel. Intervention psychoterapeutique. Violence dans la famille.

\section{Referências}

Andolfi, M. (1981). A terapia familiar. Lisboa: Vega.

Aponte, H. (1991). Training on the person of the therapist for work with the poor and minorities. The Journal of Independent Social Work, 5(3-4), 23-39.

Anderson, H., \& Goolishian, H. (1993). O cliente é o especialista. Uma abordagem para terapia a partir de uma posição de NÃO SABER. Nova Perspectiva Sistêmica, 2(3), $8-23$.

Attneave, C. (1976). Social networks as the unit of intervention. In P. Guerin Jr. (Ed.), Family therapy: theory and practice (pp. 220-232 ). New York: Gardner Press.

Bandeira, L., \& Almeida, T. M. C. (1999). Pai e avô: o caso de estupro incestuoso do pastor. In M. Suárez \& L. Bandeira (Orgs.), Violência, gênero e crime no Distrito Federal (pp 147-172). Brasília, DF: UnB/Paralelo 15. 
O Grupo Multifamiliar como um Método de Intervenção em Situações...

Barbier, R. (2002). A pesquisa-ação. Brasília, DF: Plano.

Bergman, J. (1986). Pescando barracudas: pragmática de la terapia sistemica breve. Buenos Aires, Argentina: Paidós.

Boscolo, L., Cecchin, G., Hoffman, L., \& Penn, P. (1993). A terapia familiar sistêmica de Milão. Conversações sobre teoria e prática. Porto Alegre, RS: Artes Médicas.

Bowen, E. (1976). Principles and techniques of multiple family therapy. In P. Guerin Jr. (Ed.), Family therapy: theory and practice (pp. 338-416). New York: Gardner Press.

Cirillo, S., \& Di Blasio, P. (1991). Niños maltratados. Diagnóstico y terapia familiar. Buenos Aires, Argentina: Paidós.

Corrêa, S. (2001). Violência e os direitos humanos das mulheres. In R. Novaes (Org.), Direitos humanos: temas e perspectivas (pp. 125-152.). Rio de Janeiro: Mauad.

Costa, L. F. (1998a). Reuniões multifamiliares: uma proposta de intervenção em psicologia clínica na comunidade. Tese de Doutorado, Programa de Pós Graduação em Psicologia, Universidade de São Paulo. São Paulo.

Costa, L. F. (1998b). Reuniões multifamiliares: condição de apoio, questionamento e reflexão no processo de exclusão de membros da família. Ser Social, 3, 245-272.

Costa, L. F. (1998/1999). Possibilidade de criação de um contexto educativo: grupos multifamiliares. Linhas Críticas, 4(7-8), 159-174.

Costa, L. F. (1999). O trabalho da psicologia clínica na comunidade através do psicodrama: a reunião multifamiliar. Revista Brasileira de Psicodrama, 7(2), 17-34.

Costa, L. F. (2003). E quando termina em mal me quer? Reflexões acerca do grupo multifamiliar e da visita domiciliar como instrumentos da psicologia clínica na comunidade. Brasília, DF: Universa.

Costa, L. F., Penso, M. A., \& Almeida, T. M. (2003, julho). Grupos multifamiliares em casos de litígio envolvendo abuso sexual. Trabalho apresentado no VI Conferência Internacional sobre Filosofia, Psiquiatria e Psicologia, Brasília, DF.

Costa, L. F., Penso, M. A., Gramkow, G., Santana, P., \& Ferro, V. S. (2003). Demandas judiciais: resgatando a cidadania e o sofrimento em intervenções psicossociais. In H. G. D. Lima (Orgs.). Construindo caminhos para a intervenção no contexto da justiça (pp. 125-141) Brasília, DF: TJDFT.

Costa, L. F., Penso, M. A., \& Almeida, T. M. C. (2004). Intervenções psicossociais a partir da justiça: garantia de direitos humanos para crianças e adolescentes vítimas de violência sexual. In G. Maluschke, J. S. N. F. Bucher-Maluschke, \& K. Hermans, Direitos humanos e violência: desafios da ciência e da prática (pp. 259272). Fortaleza, Ceará: Fundação Konrad Adenauer/UNIFOR. 
Costa, L. F., Santana, P., Gramkow, G., \& Ferro, V. S. (2005). O genograma de família com abuso sexual. In L. F. Costa \& T. M. C. de Almeida. Violência no cotidiano: do risco à proteção (pp. 75-86). Brasília, DF: Universa.

Dabas, L. N. (1995). A intervenção em rede. Nova Perspectiva Sistêmica, 6, 5-18.

Demo, P. (1991). Assistência social como direito da cidadania [Apostila]. Brasília, DF: DME/SAE.

Demo, (1996). Participação é conquista (3a ed.) São Paulo: Cortez.

Faleiros, E. (Org.) (2003). O abuso sexual contra crianças e adolescentes: os (des)caminhos da denúncia. Brasília, DF: Secretaria Especial dos Direitos Humanos.

Hollanda, E. (1993) Práticas alternativas de pesquisa: alguns questionamentos sobre as potencialidades e limites da pesquisa ação e pesquisa participante. In Valla, V. \& Stotz, E. (Orgs.) Participação popular, educação e saúde: teoria e prática. (pp. 2539). Rio de Janeiro: Relume Dumará

Holzmann, M. E., \& Grassano, S. M. (2002). Multifamílias. Construção de redes de afeto. Curitiba, PR: Integrada.

Lane, S. T. M., \& Sawaia, B. B. (1995). La psicología social comunitaria en Brasil. In E. Wiesenfeld \& E. Sánchez (Comp.), Psicología social comunitaria. Contribuiciones latinoamericanas (pp. 69-112). Caracas, Venezuela: Fondo Editorial Tropykos.

Laquer, P. (1976). Multiple family therapy. In P. Guerin Jr. (Ed.), Family therapy: theory and practice (pp. 405-416). New York: Gardner Press.

Laquer, P. (1983). Terapia familiar múltipla: perguntas e respostas. In D. Bloch, Técnicas de psicoterapia familiar (pp. 93-107 ). São Paulo: Atheneu.

Madanes, C., Keim, J. P., \& Smelser, D. (1997). Violencia masculina. Barcelona, España: Granica.

Maturana, H. R., \& Verden-Zöller, G. (1997). Amor y juego. Fundamentos olvidados de lo humano (5a ed.) Santiago, Chile: Instituto de Terapia Cognitiva.

Minuchin, P., Colapinto, J., \& Minuchin, S. (1999). Trabalhando com famílias pobres. Porto Alegre, RS: Artes Médicas.

Monteiro, M. R. (1979). Jogos dramáticos. São Paulo: Mc Graw Hill do Brasil.

Moreira das Neves, J. F. (2000). Violência doméstica: um problema sem fronteiras. Workshop apresentado em Ponta Delgada, Portugal.

Mejias, N. P. (1995). A atuação do psicólogo: da clínica para a comunidade. Cadernos de Psicologia, 1, 32-43. 
O Grupo Multifamiliar como um Método de Intervenção em Situações...

Miermont, J. (Dir.). (1987). Dictionnaire des thérapies familiales. Théories et pratiques. Paris: Payot.

Moreno, J. L. (1993). Psicoterapia de grupo e psicodrama (2a ed.). Campinas, SP: Psy.

Motta, J. (Org.). (1995). O jogo no psicodrama. São Paulo: Ágora.

Penso, M. A., Legnani, V., Costa, L. F., \& Antunes, C. (2005). O grupo multifamiliar com famílias de crianças e adolescentes vítimas de abuso sexual no contexto da crise. In L. F. Costa \& T. M. C. de Almeida, Violência no cotidiano: do risco à proteção (pp. 87-105). Brasília, DF: Universa.

Penso, M. A., Costa, L. F., \& Almeida, T. M. C. (2005). Pequenas histórias, grandes violencias. In L. F. Costa \& T. M. C. de Almeida, Violência no cotidiano: do risco à proteção (pp. 125-137). Brasília, DF: Universa.

PNUD (1996). Relatório sobre o desenvolvimento humano no Brasil. Rio de Janeiro: IPEA.

Póvoa, M. L. S., \& Sudbrack, M. F. O. (2003). Reuniões multifamiliares: acolhendo o adolescente usuário de drogas e sua família no contexto da justiça. In M. F. O. Sudbrack, M. I. G. Conceição, \& M. T. Silva (Orgs.), Adolescentes e drogas no contexto da justiça (pp. 147-166). Brasília, DF: Plano.

Ravazzola, M. C. (1997). Historias infames: los maltratos en las relaciones. Buenos Aires: Paidós.

Saidón, O. (1995). Las redes: pensar de otro modo. In E. Dabas \& D. Najmanovich (Orgs.), Redes. El lenguaje de los vínculos. Hacia la reconstrucción y el fortalecimiento de la sociedad civil (pp. 203-207). Buenos Aires, Argentina: Paidós.

Santos, B. S. (1999). Um discurso sobre as ciências (11a ed.). Porto, Portugal: Afrontamento.

Selosse, J. (1989). Les intervections des psychologues en justice. Psychologie Française, 34(4), 293-300.

Sluzki, C. E. (1996). Violência familiar e violência política: implicações terapêuticas de um modelo geral. In D. F. Schnitman (Org.), Novos paradigmas, cultura $e$ subjetividade (pp. 228-243). Porto Alegre, RS: Artes Médicas.

Thiollent, M. (1986) Metodologia da pesquisa ação. São Paulo: Cortez.

UNICEF (2001). Para toda criança. São Paulo: Ática.

Vaconcellos, M. J. E. (2002). Pensamento sistêmico. O novo paradigma da ciência. Campinas, SP: Papirus.

Violencia sexual infantil no contexto judicial e terapêutico (2002, 11 de outubro). Fórum de debates, Brasília, DF: Tribunal de Justiça do Distrito Federal. 
Liana Fortunato Costa, Maria Aparecida Penso e Tânia M. Campos de Almeida

Yozo, R. Y. K. (1996). 100 jogos para grupos. São Paulo: Ágora.

Recebido em: 19.10 .2005

Revisto e encaminhado em: 05.12.2005

Aceito em: 12.12.2005 